\title{
Effects of CD73 on human colorectal cancer cell growth in vivo and in vitro
}

\author{
RUIMIN WU*, YIJIA CHEN*, FUYAN LI, WEI LI, HONG ZHOU, YI YANG and ZHIJUN PEI \\ Department of PET Center, Taihe Hospital, Hubei University of Medicine, Shiyan, Hubei 442000, P.R. China
}

Received September 11, 2015; Accepted November 23, 2015

DOI: $10.3892 /$ or.2015.4512

\begin{abstract}
The purpose of the present study was to explore the role and mechanism of extracellular ecto-5'-nucleotidase (CD73) in human colorectal cancer growth. Firstly, CD73 expression was detected in colorectal cancer cell lines both at the mRNA and protein levels. Secondly, recombinant CD73 interference and overexpression lentiviruses were used, respectively. Colony formation assay, CCK-8 assay and flow cytometry were used to investigate the impact of CD73 on colorectal cancer cell proliferation and cell cycle distribution. Then, adenosine and CD73 enzyme activity inhibitor (APCP) were used to study the effect of CD73 on Epidermal growth factor receptor (EGFR) and $\beta$-catenin/cyclin D1 signaling pathways. Finally, a human colorectal cancer transplantation nude mouse model was used to observe the effect of CD73 on tumor growth in vivo. As the results showed, CD73 was highly expressed in the colorectal cancer cell lines. CD73 promoted colorectal cancer cell proliferation both in vivo and in vitro. CD73 activated EGFR and the $\beta$-catenin/cyclin D1 signaling pathways through its enzyme and non-enzyme activities. All of the results confirmed that CD73 promotes the growth of human colorectal cancer cells through EGFR and the $\beta$-catenin/cyclin D1 signaling pathway. CD73 may be used as a valuable biomarker of colorectal cancer.
\end{abstract}

Correspondence to: Dr Zhijun Pei, Department of PET Center, Taihe Hospital, Hubei University of Medicine, Shiyan, Hubei 442000, P.R. China

E-mail: zjphbsy@163.com

*Contributed equally

Abbreviations: AMP, adenosine monophosphate; APCP $\alpha, \beta$-methylene ADP; CD73, ecto-5'-nucleotidase, CFR, clone formation rate; DMEM, Dulbecco's modified Eagle's medium; EGFR, epidermal growth factor receptor; FBS, fetal bovine serum; GPI, glycosyl phosphatidylinositol; MOI, multiplicity of infection; PI, proliferation index

Key words: $\beta$-catenin/cyclin D1, adenosine, colorectal cancer, CD73, EGFR

\section{Introduction}

Colorectal cancer is one of the most common cancers and is the leading cause of cancer-related deaths worldwide $(1,2)$. Colorectal cancer is highly treatable when diagnosed and surgically removed at an early stage. Unfortunately, many patients are diagnosed with (distant) metastasis either during follow-up or at first presentation, $80-90 \%$ of which are unresectable $(3,4)$. Despite considerable improvements in the treatment of colorectal cancer over the last few decades, the only option for unresectable metastatic CRC (mCRC) remains palliative systemic treatment $(5,6)$. Recently, targeted and biological therapeutics have made substantial advances in mCRC treatment, and have prolonged overall survival and disease-free survival of patients, with fewer adverse effects than conventional chemotherapy $(7,8)$. Since these therapeutics act on specific target proteins, they are restricted to certain individuals according to their molecular profiles. Therefore, more specific biomarkers, which determine the biological nature and behavior of colorectal cancer, is needed to benefit more patients $(8,9)$.

Ecto-5'-nucleotidase (CD73), a glycosylphosphatidylinositol-linked 70-kDa cell-surface molecule, is expressed on many cell types, including subsets of lymphocytes, endothelial cells and epithelial cells (10). CD73 expression was found abnormally upregulated in many types of cancer tissues, such as colorectal, gastric, liver, ovarian and breast cancer (11-14). Studies have shown that CD73 on tumor cells is associated with tumorigenesis and tumor progression through inhibition of $\mathrm{CD}^{+} \mathrm{T}$ cells and NK cell proliferation, while increasing suppressive immune subsets such as regulatory T cells (Tregs), $\mathrm{B}$ cells, and myeloid-derived suppressor cells (15-18). Besides being originally defined as a lymphocyte differentiation antigen, CD73 has been identified as a co-signaling molecule on $\mathrm{T}$ cells and as an adhesion molecule required for lymphocyte binding to the endothelium $(19,20)$.

More significantly, CD73 is a critical ectoenzyme in purine metabolism, which hydrolyzes extracellular AMP to adenosine (21). Thus, CD73 is a switch molecule of adenosine-related signaling pathways, which are important in a series of biological events, such as cell survival, proliferation and cell motility $(22,23)$. In this study, we aimed to verify the hypothesis that CD73 promotes human colorectal cancer cell growth through its enzyme and non-enzyme activities, except for immune-related mechanisms. 


\section{Materials and methods}

Cell culture. The colorectal cancer cell lines (RKO, SW480, HCT-15, LoVo and KM12) used in this study were obtained from the American Type Culture Collection (ATCC; Manassas, VA, USA), and cultured in high glucose Dulbecco's modified Eagle's medium (DMEM) with $10 \%$ fetal bovine serum (both from Gibco, USA) at $37^{\circ} \mathrm{C}$ in $5 \% \mathrm{CO}_{2}$, under saturated humidity conditions.

Real-time RT-PCR and western blot analysis. Total RNA and proteins were routinely isolated from the cultured cells. Then, mRNA and protein expression levels were determined, respectively by real-time RT-PCR and western blot assays, where the housekeeping gene $\beta$-actin was used as control. Primary antibodies against $\beta$-actin, CD73, EGFR, $\beta$-catenin and cyclin D1 (Santa Cruz Biotechnology, Santa Cruz, CA, USA) were used at a dilution of 1:500 overnight at $4^{\circ} \mathrm{C}$, respectively. HRP-labeled second antibodies (Santa Cruz Biotechnology) were used at a dilution of 1:1,000 for $1 \mathrm{~h}$. To determine whether hydrolase activity of CD73 affects epidermal growth factor receptor (EGFR) expression, similar analyses were performed with cells pretreated with CD73 enzyme activity inhibitor APCP $(10 \mu \mathrm{M})$ for $1 \mathrm{~h}$ or adenosine $(20-200 \mu \mathrm{M})$ for $24 \mathrm{~h}$.

Recombinant lentiviruses. CD73 interference and overexpressing recombinant lentiviruses were constructed using a 'three plasmid system' (Genechem, China). Interference-interference and overexpression sequences of CD73 were designed according to its gene sequence (gene ID: 4907). The multiplicity of infection (MOI) of the recombinant lentivirus in adherent monolayer colorectal cancer cells was 50. The effects of the recombinant lentivirus were observed at 1 week after infection.

Colony formation assay. Approximately $1 \times 10^{3}$ colorectal cancer cells infected with the recombinant lentiviruses were plated in 60-mm culture dishes, fixed with ethanol and stained with $0.5 \%$ crystal violet 2 weeks later. The clone formation rate $(\mathrm{CFR})=$ clone counts/seeded cell counts $\times 100 \%$.

Cell Counting Kit-8 (CCK-8) assay. Adherent monolayer colorectal cancer cells in a 96 -well plate were treated according to the manufacturer's instructions provided in the CCK-8 assay (Dojindo Laboratories, Gaithersburg, MD, USA). The cells were incubated in $10 \mu \mathrm{lCCK}-8$ agents for $1 \mathrm{~h}$ at $37^{\circ} \mathrm{C}$.

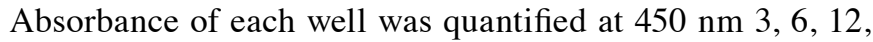
24 and $48 \mathrm{~h}$ later, respectively.

Cell cycle analysis. Adherent monolayer colorectal cancer cells were ethanol-fixed and stained with propidium iodide in buffer with RNase A. The DNA content was assessed using flow cytometer (Becton-Dickinson, San Jose, CA, USA). The proliferation index $(\mathrm{PI})=[(\mathrm{G} 2 / \mathrm{M}+\mathrm{S}) /(\mathrm{G} 0 / \mathrm{G} 1+\mathrm{G} 2 / \mathrm{M}+\mathrm{S})] \times 100 \%$.

Tumorigenicity assay. LoVo cells infected with CD73 interference and control lentiviruses were injected subcutaneously into 4-week nude mice $\left(2 \times 10^{6}\right.$ cells/mouse), respectively. The tumors were measured every 3 days. The mean tumor volume was calculated as follows: $0.5 \mathrm{x} \mathrm{a} \mathrm{x} \mathrm{b}$ (' $\mathrm{a}$ ' is the largest
A
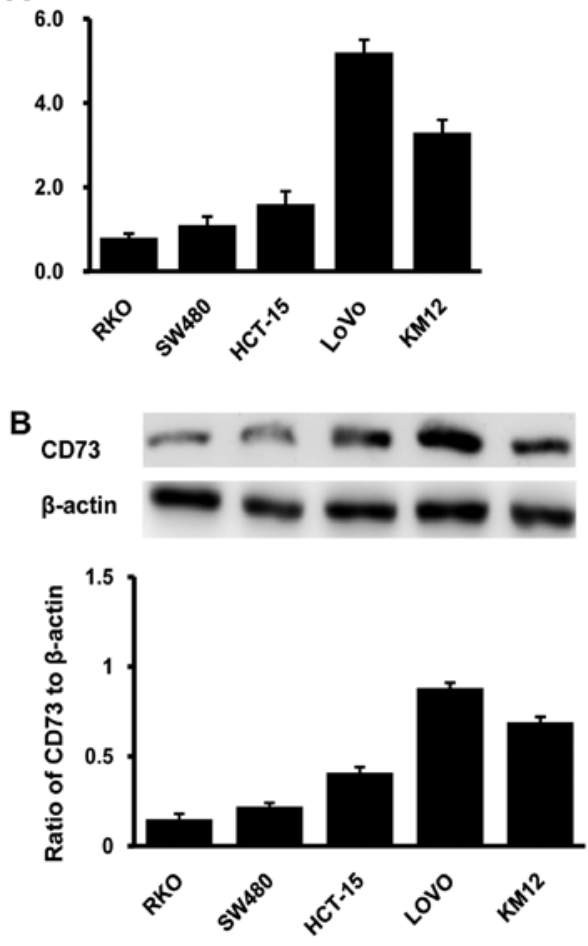

C
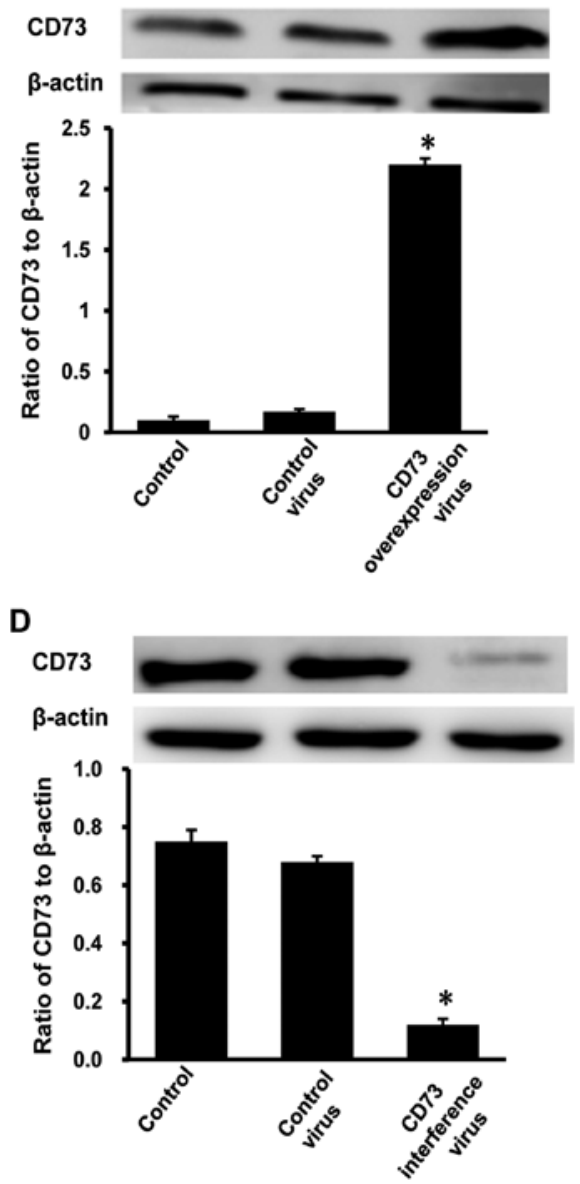

Figure 1. CD73 expression in colorectal cancer cell lines and the effects of recombinant lentiviruses. CD73 expression at both the mRNA (A) and protein (B) level $(n=3)$ was higher in the LoVo and KM12 cells with higher malignant potential than these levels in the other cell lines with moderate malignant potential. Recombinant lentiviruses significantly altered CD73 expression in the colorectal cancer cells $(\mathrm{C}$ and $\mathrm{D})\left(\mathrm{n}=3,{ }^{*} \mathrm{P}<0.05\right)$. 

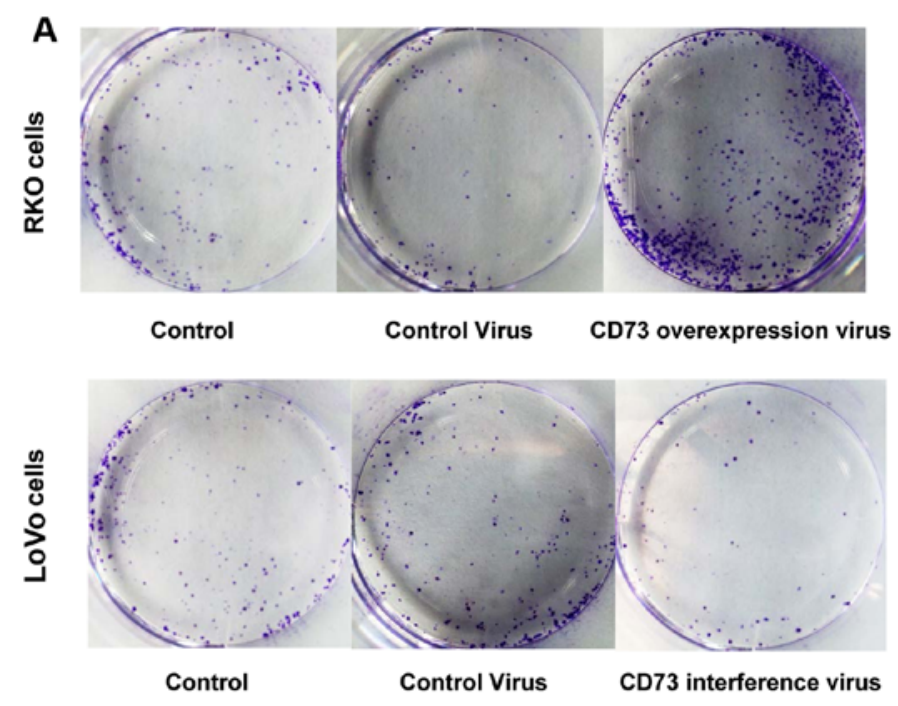

B
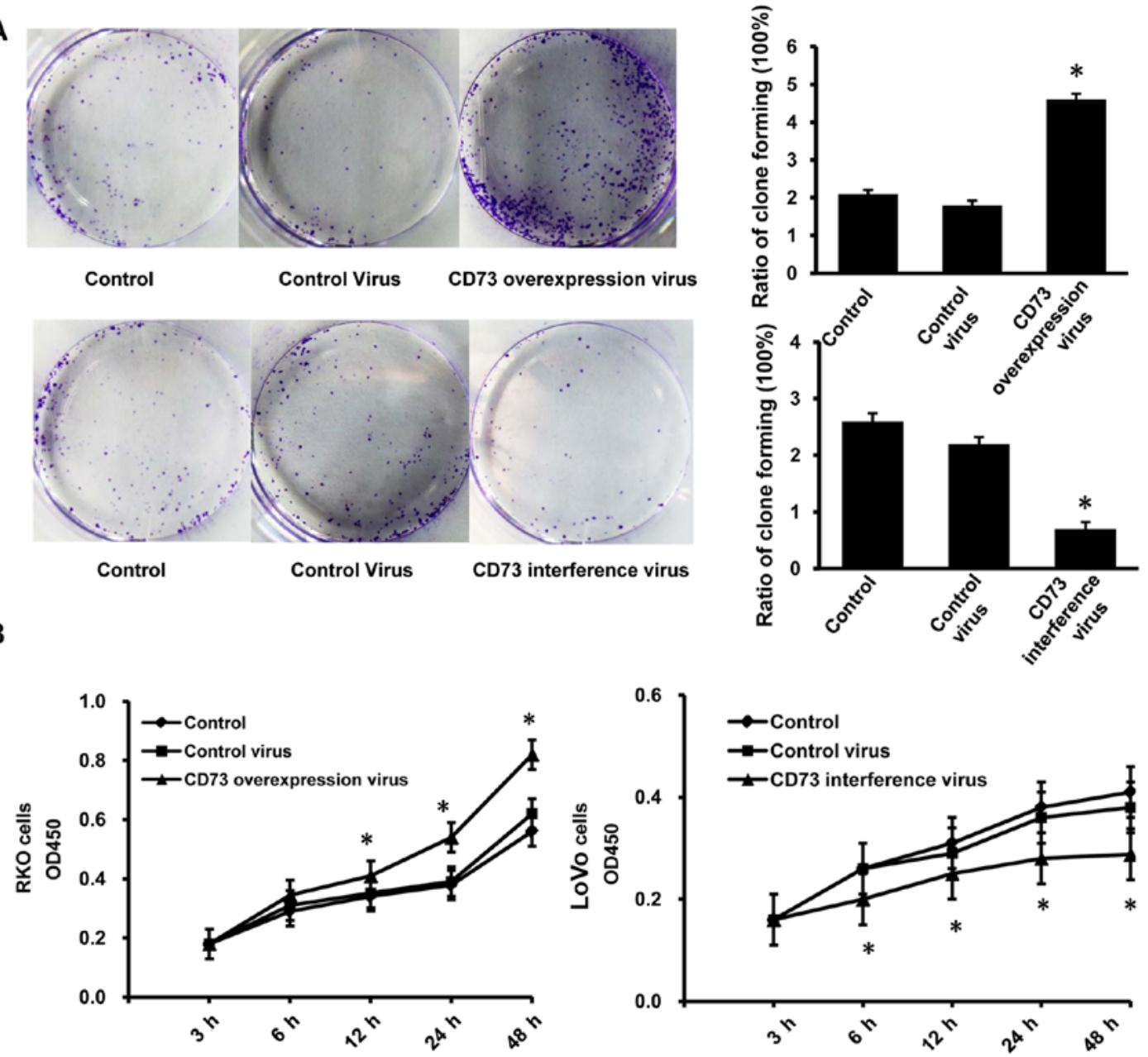

Figure 2. Effects of CD73 on the cell growth of colorectal cancer cells. CD73 overexpression lentiviruses promoted the growth of RKO cells while CD73 interference lentiviruses decreased the growth of LoVo cells in the colony formation assay (A) and CCK-8 assay (B).

diameter, 'b' is the perpendicular diameter). Tumors were excised and weighed 3 weeks after injection.

Statistical analysis. All analysis of data was performed using SPSS 11.5 software. $\mathrm{P}<0.05$ was considered to indicate a statistically significant result.

\section{Results}

CD73 expression in colorectal cancer cell lines. CD73 expression was examined in five human colorectal cancer cell lines (RKO, SW480, HCT-15, KM12 and LoVo) by real-time PCR and western blot analysis (Fig. 1A and B). CD73 expression was higher in the LoVo and KM12 cells with more malignant potential at both the mRNA and protein levels. On contrast, CD73 mRNA and protein expression was lower in the RKO, SW480 and HTC-15 cell lines with moderate malignant potential.

Effects of the recombinant lentivirus infection. Recombinant CD73 interference lentiviruses were infected into human colorectal cancer LoVo cells with a high background expression of CD73. Recombinant CD73 overexpression lentiviruses were infected into the RKO cells with a low background CD73 expression. In line with our expectation, both of the recom- binant lentiviruses achieved a significant change in CD73 expression at the mRNA and protein levels (Fig. 1C and D).

CD73 promotes colorectal cancer cell growth and cell cycle in vitro. In the colony formation (Fig. 2A) and CCK-8 assays (Fig. 2B), colony formation ability and cell viability of RKO cells were increased after infection with the CD73 overexpression lentivirus. On the other hand, cell viability and colony formation ability of LoVo cells were decreased after infection with the CD73 interference lentivirus. More RKO cells were detected by flow cytometry to enter the $S$ phase from the G0/G1 phase after infection with CD73 overexpression lentivirus, with an increased PI (Fig. 3A). On the contrary, more LoVo cells were found to enter the G0/G1 phase from the $S$ phase after infection with the CD73 interference lentivirus, resulting in decreased PI (Fig. 3B).

CD73 increases EGFR and $\beta$-catenin/cyclin D1 expression. The important cell cycle protein cyclin D1, as well as its major transcription regulation molecule $\beta$-catenin, were found to be increased in the RKO cells infected with the CD73 overexpression lentivirus (Fig. 4A), while expression levels were decreased after infection of the CD73 interference lentivirus in the LoVo cells (Fig. 4B). EGFR, the critical cell growth 

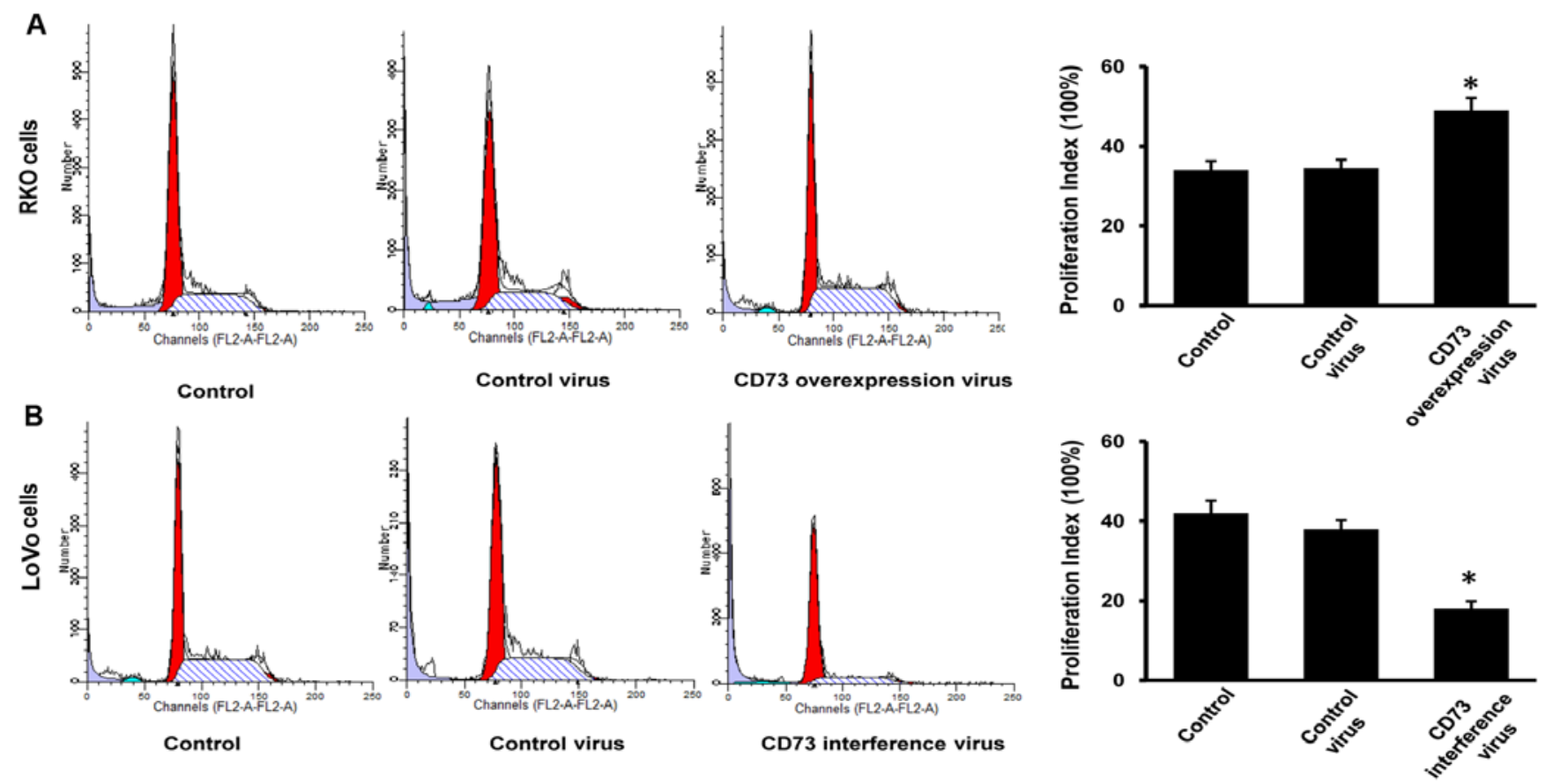

Figure 3. Effect of CD73 on the cell cycle distribution of colorectal cancer cells. CD73 overexpression lentiviruses promoted the proliferation index (PI) of RKO cells (A) while CD73 interference lentiviruses decreased the PI of LoVo cells (B) in the cell cycle assays. PI $=[(\mathrm{G} 2 / \mathrm{M}+\mathrm{S}) /(\mathrm{G} 0 / \mathrm{G} 1+\mathrm{S}+\mathrm{G} 2 / \mathrm{M})] \mathrm{x} 100 \%$ $(\mathrm{n}=3, \mathrm{P}<0.05)$.
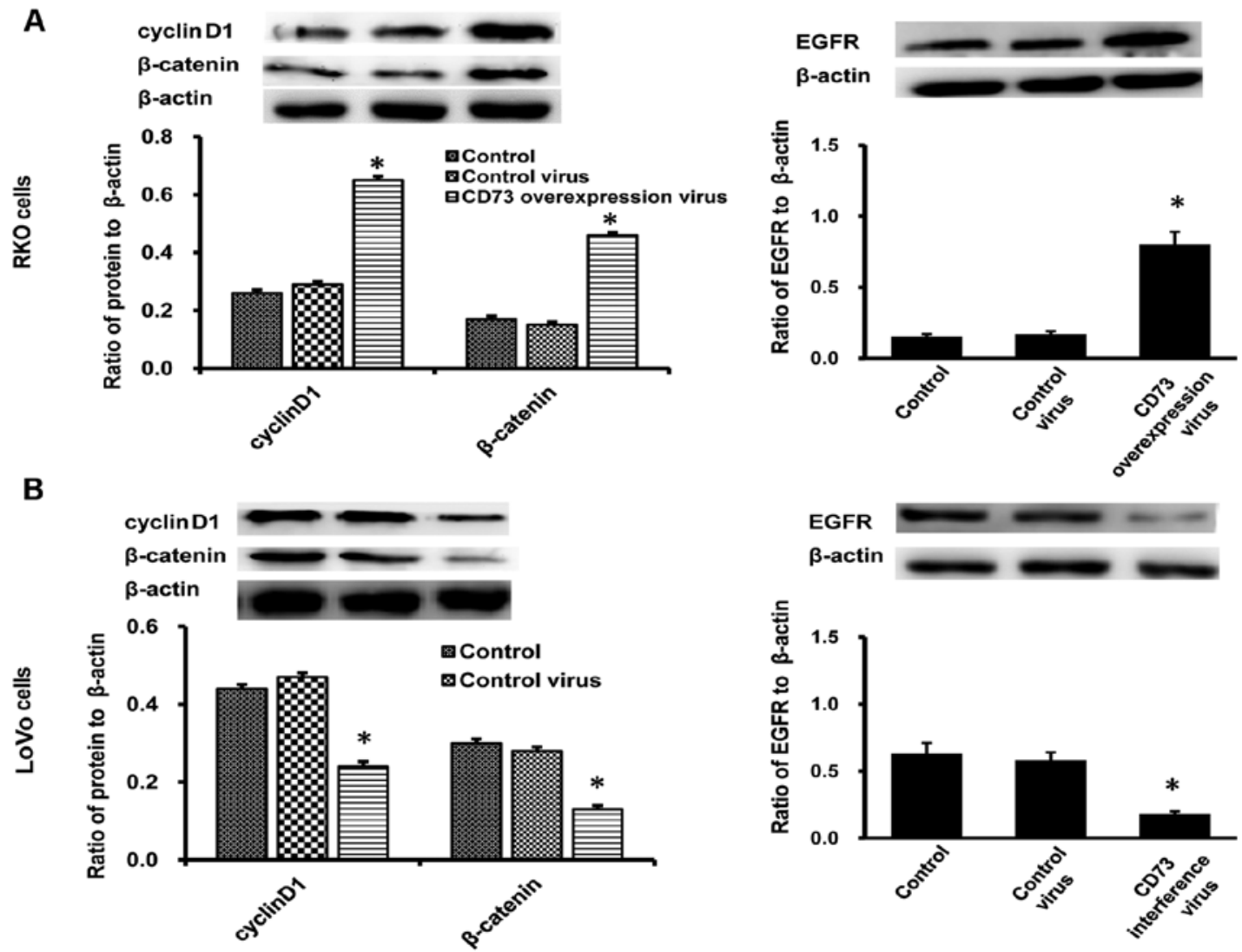

Figure 4. Effects of CD73 on EGFR and $\beta$-catenin/cyclin D1 expression in colorectal cancer cells. CD73 overexpression lentiviruses increased EGFR and $\beta$-catenin/cyclin D1 expression in the RKO cells (A), while CD73 interference lentiviruses decreased the expression levels in the LoVo cells (B) (n=3, $\left.{ }^{*} \mathrm{P}<0.05\right)$.

signaling pathway molecule and the major target of colorectal cancer biological therapeutics, was also found to be increased after CD73 was overexpressed (Fig. 4A), but decreased after CD73 was silenced (Fig. 4B). 


\section{A}
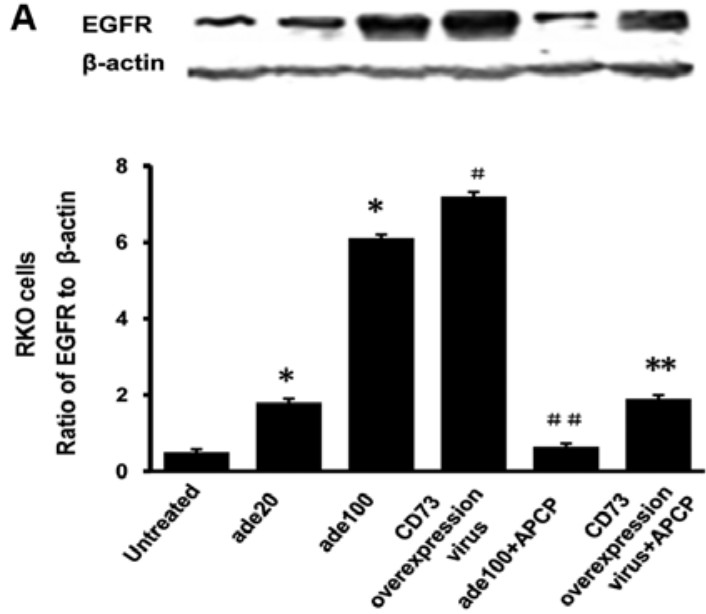
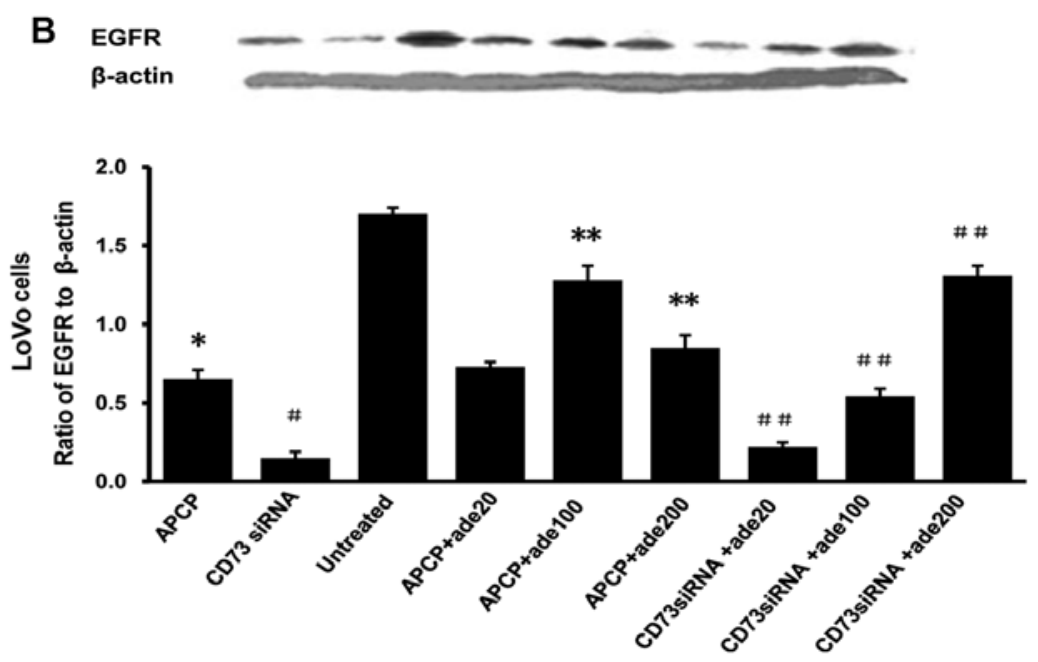

Figure 5. Role of adenosine in the effects of CD73 on EGFR expression. Adenosine (ade) increased EGFR expression in the RKO cells (A) in a concentration-dependent manner, but at a lower degree than the CD73 overexpression lentiviruses. APCP reversed the effects of adenosine (completely) and CD73 overexpression lentiviruses (partially). On the other hand, APCP exhibited a weaker effect than CD73 siRNA lentiviruses on EGFR expression in the LoVo cells (B). Similarly, adenosine reversed the effects of APCP (completely) and CD73 siRNA lentiviruses (partially) $\left(\mathrm{n}=3,{ }^{*} \mathrm{P}<0.05\right)$.
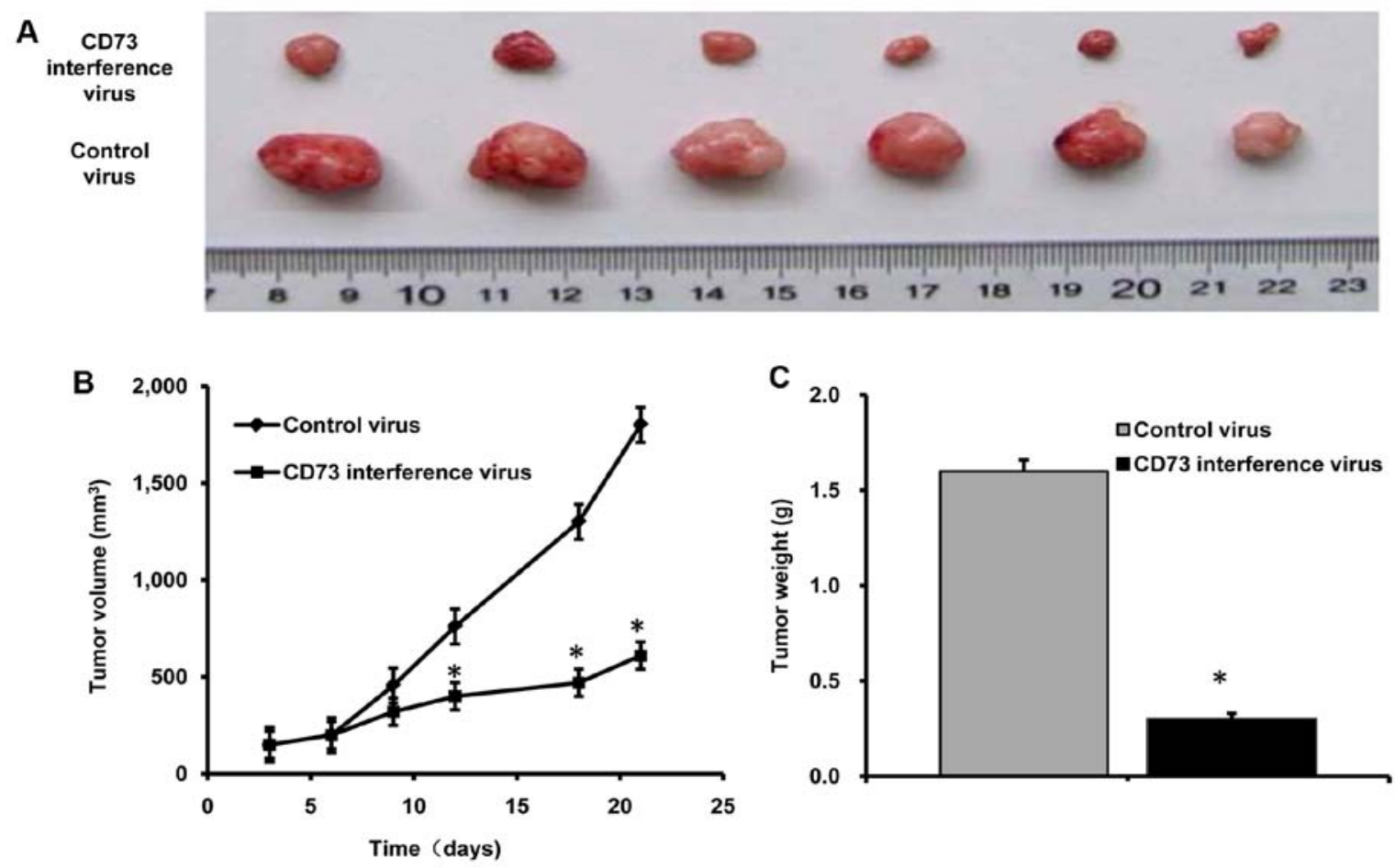

Figure 6. Effects of CD73 on colorectal cancer cell growth in vivo. Slower growth, smaller volume (A and B) and lower weight (C) were observed in nude mice subcutaneously injected with cancer cells treated with CD73 interference lentiviruses when compared with these parameters in nude mice injected with cancer cells treated with the control lentiviruses $\left(\mathrm{n}=6,{ }^{*} \mathrm{P}<0.05\right)$.

The role of adenosine in the effects of CD73 on EGFR expression. Similar to the CD73 overexpression lentivirus, adenosine also increased the expression of EGFR in the RKO cells, but to a lower degree. APCP, a CD73 enzyme activity inhibitor, completely reversed the effects of adenosine and partially the effects of the CD73 overexpression virus (Fig. 5A). In contrast, APCP had a weaker effect than the CD73 interference lentivirus on the expression of EGFR in the LoVo cells. Similarly, adenosine completely reversed the effects of APCP and partially the effects of the CD73 interference virus (Fig. 5B). All these results suggested that the mechanism of the effects of CD73 on EGFR expression was far more marked than adenosine alone.

CD73 promotes colorectal cancer cell growth in vivo. LoVo cells $\left(2 \times 10^{6}\right)$ infected with the CD73 interference or control lentivirus were injected subcutaneously into athymic nude mice. Tumor growth was obviously slower in the mice injected 
with the CD73-silenced LoVo cells than the control 20 days after injection (Fig. 6A and B). The weight of the tumors derived from the CD73-silenced LoVo cells was lower than the control (Fig. 6C). The results suggested that CD73 promoted the tumorigenicity of colorectal cancer cells in vivo.

\section{Discussion}

Metastatic colorectal cancer (mCRC) has a high incidence and mortality rate worldwide, and the effect of surgery remains limited $(2,4)$. Molecular targeted therapy for mCRC has made progress in recent decades. For example, monoclonal antibody (mAb) drugs targeting EGFR (24), such as cetuximab (25) and panitumumab (26), have been recommended to treat mCRC singly or combined with systemic chemotherapy, for prolonging overall and disease-free survival $(7,8)$. Finding more promising biomarkers for targeted therapy has good prospects in mCRC treatment $(27,28)$.

CD73 is a glycosylphosphatidylinositol (GPI) anchored cell surface protein (16). Its expression is commonly upregulated in many types of cancers, such as colorectal, gastric, liver, ovarian and breast cancer (29-31). Studies have proved that CD73 promotes cancer progression through regulating tumor immune surveillance $(16,32,33)$. CD73 is expected to be a promising biomarker for cancer therapy $(11,34)$. Moreover, in this study, we found that CD73 promotes colorectal cancer growth through mechanisms other than immunoregulation.

Firstly, our results showed that CD73 expression was significantly higher in colorectal cancer cells with high malignant potential than in colorectal cancer cells with low malignant potential, which suggest that CD73 expression may be associated with colorectal cancer malignancy. Furthermore, colony formation, CCK-8 and tumorigenicity assays in this study showed that CD73 promoted colorectal cancer cell growth both in vitro and in vivo. Flow cytometry showed that CD73 promoted colorectal cancer growth by regulating more cells into the $S$ phase from the G0/G1 phase, resulting in an improved PI. These findings were consistent with the results of other research in other types of cancers $(15,35,36)$.

Wnt/ $\beta$-catenin/cyclin D1 is a classic signaling pathway for controlling embryonic growth and development, stem cell self-renewal, tissue structure maintenance and tumor progression $(37,38)$. Cyclin D1 is a critical cyclin for regulating the colorectal cancer cell cycle (39). $\beta$-catenin is the major transcription regulator of cyclin D1, the abnormalities of which are commonly found in colorectal cancer $(40,41)$. Our results showed that CD73 promoted both $\beta$-catenin and cyclin D1 expression, which well explained the effects of CD73 on colorectal cancer cell growth. EGFR is the critical molecule of many signaling pathways which control cell growth and is the major target of colorectal cancer biological therapeutics (24). Co-expression of CD73 and EGFR has been found in other types of cancers $(34,36)$. Consistently, it was found in this study that CD73 promoted EGFR expression. The exact interactions among CD73, EGFR and $\beta$-catenin/cyclin D1 warrant further exploration.

In addition to immunoregulatory effects, CD73 plays a crucial role in adenosinergic signaling through catalyzing AMP into adenosine. Furthermore, CD73 also acts as an adhesion regulating molecule between cancer cells and extra- cellular matrix (ECM) components, which is not dependent on its enzymatic activity $(19,20)$. In this study, we found that both enzymatic activity and non-enzymatic activity were involved in the regulation of CD73 in colorectal cancer cell growth, since adenosine and CD73 enzyme activity inhibitor APCP could only partly achieve the effects of the CD73 overexpression and interference virus, respectively. These results are supported by many studies in other cancers $(42,43)$, suggesting that adenosine-related pathways and other signaling pathways warrant further study in colorectal cancer growth.

In conclusion, we found that $\mathrm{CD} 73$ promotes the growth of human colorectal cancer cells in vitro and in vivo. The effects of CD73 may be related to EGFR and $\beta$-catenin/cyclin D1 pathways. Our results suggest that CD73 may be a potential biomarker of colorectal cancer.

\section{Acknowledgements}

This study was supported by the National Natural Science Foundation of China (grants no. 81401447).

\section{References}

1. Brody H: Colorectal cancer. Nature 521: S1, 2015.

2. Paulson EC, Veenstra CM, Vachani A, Ciunci CA and Epstein AJ: Trends in surveillance for resected colorectal cancer, 2001-2009. Cancer 121: 3525-3533, 2015.

3. van Vugt JL, Reisinger KW, Derikx JP, Boerma D and Stoot JH: Improving the outcomes in oncological colorectal surgery. World J Gastroenterol 20: 12445-12457, 2014.

4. Prorokov VV, Vlasov OA and Tupitsyn NN: Current state of the problem of treatment and prognosis of colorectal cancer. Vopr Onkol 60: 28-33, 2014 (In Russian).

5. Li L and Ma BB: Colorectal cancer in Chinese patients: Current and emerging treatment options. Onco Targets Ther 7: 1817-1828, 2014.

6. Vignali A and De Nardi P: Multidisciplinary treatment of rectal cancer in 2014: Where are we going? World J Gastroenterol 20: 11249-11261, 2014.

7. Binefa G, Rodríguez-Moranta F, Teule A and Medina-Hayas M: Colorectal cancer: From prevention to personalized medicine. World J Gastroenterol 20: 6786-6808, 2014.

8. Ahmed S, Johnson K, Ahmed O and Iqbal N: Advances in the management of colorectal cancer: From biology to treatment. Int J Colorectal Dis 29: 1031-1042, 2014.

9. Morris V and Kopetz S: Clinical biomarkers in colorectal cancer. Clin Adv Hematol Oncol 11: 768-776, 2013.

10. Chen Y, Thelin WR, Yang B, Milgram SL and Jacobson K: Transient anchorage of cross-linked glycosyl-phosphatidylinositol-anchored proteins depends on cholesterol, Src family kinases, caveolin, and phosphoinositides. J Cell Biol 175: 169-178, 2006.

11. Liu N, Fang XD and Vadis Q: CD73 as a novel prognostic biomarker for human colorectal cancer. J Surg Oncol 106: 918-920, 2012.

12. Zhi X, Wang Y, Zhou X, Yu J, Jian R, Tang S, Yin L and Zhou P: RNAi-mediated CD73 suppression induces apoptosis and cell-cycle arrest in human breast cancer cells. Cancer Sci 101: 2561-2569, 2010

13. Gao ZW, Dong K and Zhang HZ: The roles of CD73 in cancer. Biomed Res Int 2014: 460654, 2014.

14. Häusler SF, Montalbán del Barrio I, Strohschein J, Chandran PA, Engel JB, Hönig A, Ossadnik M, Horn E, Fischer B, Krockenberger M, et al: Ectonucleotidases CD39 and CD73 on OvCA cells are potent adenosine-generating enzymes responsible for adenosine receptor 2A-dependent suppression of T cell function and NK cell cytotoxicity. Cancer Immunol Immunother 60: 1405-1418, 2011.

15. Stagg J, Divisekera U, McLaughlin N, Sharkey J, Pommey S, Denoyer D, Dwyer KM and Smyth MJ: Anti-CD73 antibody therapy inhibits breast tumor growth and metastasis. Proc Natl Acad Sci USA 107: 1547-1552, 2010. 
16. Beavis PA, Stagg J, Darcy PK and Smyth MJ: CD73: A potent suppressor of antitumor immune responses. Trends Immunol 33: 231-237, 2012.

17. Stagg J, Beavis PA, Divisekera U, Liu MC, Möller A, Darcy PK and Smyth MJ: CD73-deficient mice are resistant to carcinogenesis. Cancer Res 72: 2190-2196, 2012.

18. Zhang B: CD73 promotes tumor growth and metastasis. Oncoimmunology 1: 67-70, 2012.

19. Resta R and Thompson LF: T cell signalling through CD73. Cell Signal 9: 131-139, 1997.

20. Jin D, Fan J, Wang L, Thompson LF, Liu A, Daniel BJ, Shin T, Curiel TJ and Zhang B: CD73 on tumor cells impairs antitumor T-cell responses: A novel mechanism of tumor-induced immune suppression. Cancer Res 70: 2245-2255, 2010.

21. Knapp K, Zebisch M, Pippel J, El-Tayeb A, Müller CE and Sträter N: Crystal structure of the human ecto-5'-nucleotidase (CD73): Insights into the regulation of purinergic signaling. Structure 20: 2161-2173, 2012.

22. Deaglio S and Robson SC: Ectonucleotidases as regulators of purinergic signaling in thrombosis, inflammation, and immunity. Adv Pharmacol 61: 301-332, 2011.

23. Young A, Mittal D, Stagg J and Smyth MJ: Targeting cancer-derived adenosine: New therapeutic approaches. Cancer Discov 4: 879-888, 2014.

24. Lee MS and Kopetz S: Current and future approaches to target the epidermal growth factor receptor and its downstream signaling in metastatic colorectal cancer. Clin Colorectal Cancer 14: 203-218, 2015.

25. Pietrantonio F, Petrelli F, Coinu A, Di Bartolomeo M, Borgonovo K, Maggi C, Cabiddu M, Iacovelli R, Bossi I, Lonati $\mathrm{V}$, et al: Predictive role of BRAF mutations in patients with advanced colorectal cancer receiving cetuximab and panitumumab: A meta-analysis. Eur J Cancer 51: 587-594, 2015.

26. Krawczyk PA and Kowalski DM: Genetic and immune factors underlying the efficacy of cetuximab and panitumumab in the treatment of patients with metastatic colorectal cancer. Contemp Oncol (Pozn) 18: 7-16, 2014.

27. Coget J, Borrini F, Susman S and Sabourin JC: Colorectal carcinomas in 2013: The search for powerful prognostic markers is still on the go! Cancer Biomark 14: 145-150, 2014.

28. Sideris M and Papagrigoriadis S: Molecular biomarkers and classification models in the evaluation of the prognosis of colorectal cancer. Anticancer Res 34: 2061-2068, 2014.

29. Häusler SF, Del Barrio IM, Diessner J, Stein RG, Strohschein J, Hönig A, Dietl J and Wischhusen J: Anti-CD39 and anti-CD73 antibodies A1 and 7G2 improve targeted therapy in ovarian cancer by blocking adenosine-dependent immune evasion. Am J Transl Res 6: 129-139, 2014.

30. Wu XR, He XS, Chen YF, Yuan RX, Zeng Y, Lian L, Zou YF, Lan N, Wu XJ and Lan P: High expression of CD73 as a poor prognostic biomarker in human colorectal cancer. J Surg Oncol 106: 130-137, 2012.
31. Yang Q, Du J and Zu L: Overexpression of CD73 in prostate cancer is associated with lymph node metastasis. Pathol Oncol Res 19: 811-814, 2013

32. Wang LL, Tang HP, Shi GC, Wan HY, Tang W, Hou XX, Pan LN, Shi BY and Tao LQ: CD39/CD73 and the imbalance of Th17 cells and regulatory T cells in allergic asthma. Mol Med Rep 8: 1432-1438, 2013.

33. Smyth LA, Ratnasothy K, Tsang JY, Boardman D, Warley A, Lechler R and Lombardi G: CD73 expression on extracellular vesicles derived from $\mathrm{CD} 4{ }^{+} \mathrm{CD} 25^{+} \mathrm{Foxp}^{+} \mathrm{T}$ cells contributes to their regulatory function. Eur J Immunol 43: 2430-2440, 2013.

34. Zhi X, Wang Y, Yu J, Yu J, Zhang L, Yin L and Zhou P: Potential prognostic biomarker CD73 regulates epidermal growth factor receptor expression in human breast cancer. IUBMB Life 64: 911-920, 2012.

35. Zhou X, Zhi X, Zhou P, Chen S, Zhao F, Shao Z, Ou Z and Yin L: Effects of ecto-5'-nucleotidase on human breast cancer cell growth in vitro and in vivo. Oncol Rep 17: 1341-1346, 2007.

36. Zhi X, Chen S, Zhou P, Shao Z, Wang L, Ou Z and Yin L: RNA interference of ecto-5'-nucleotidase (CD73) inhibits human breast cancer cell growth and invasion. Clin Exp Metastasis 24: 439-448, 2007.

37. Ring A, Kim YM and Kahn M: Wnt/catenin signaling in adult stem cell physiology and disease. Stem Cell Rev 10: 512-525, 2014.

38. Lee JK, Park SR, Jung BK, Jeon YK, Lee YS, Kim MK, Kim YG, Jang JY and Kim CW: Exosomes derived from mesenchymal stem cells suppress angiogenesis by down-regulating VEGF expression in breast cancer cells. PLoS One 8: e84256, 2013.

39. Gopalakrishnan N, Saravanakumar M, Madankumar P, Thiyagu $\mathrm{M}$ and Devaraj $\mathrm{H}$ : Colocalization of $\beta$-catenin with Notch intracellular domain in colon cancer: A possible role of Notch1 signaling in activation of cyclinD1-mediated cell proliferation. Mol Cell Biochem 396: 281-293, 2014.

40. Horst D: Plasticity of WNT signaling activity in colorectal cancer. Pathologe 33 (Suppl 2): 194-197, 2012 (In German).

41. Sebio A, Kahn M and Lenz HJ: The potential of targeting Wnt/ $\beta$-catenin in colon cancer. Expert Opin Ther Targets 18: 611-615, 2014.

42. Wang L, Tang S, Wang Y, Xu S, Yu J, Zhi X, Ou Z, Yang J, Zhou P and Shao Z: Ecto-5'-nucleotidase (CD73) promotes tumor angiogenesis. Clin Exp Metastasis 30: 671-680, 2013.

43. Wang L, Zhou X, Zhou T, Ma D, Chen S, Zhi X, Yin L, Shao Z, Ou Z and Zhou P: Ecto-5'-nucleotidase promotes invasion, migration and adhesion of human breast cancer cells. J Cancer Res Clin Oncol 134: 365-372, 2008. 